\title{
The nature and influence of pharmaceutical industry involvement in asthma trials
}

\author{
Kenneth Bond BEd MA ${ }^{1}$, Carol Spooner BScN MSc${ }^{2}$, Lisa Tjosvold MLIS ${ }^{3}$, \\ Catherine Lemière $\mathrm{MD} \mathrm{MSc}^{4}$, Brian $\mathrm{H}$ Rowe MD MSc CCFP(EM) FCCP5
}

\begin{abstract}
K Bond, C Spooner, L Tjosvold, C Lemière, BH Rowe. The nature and influence of pharmaceutical industry involvement in asthma trials. Can Respir J 2012;19(4):267-271.
\end{abstract}

BACKGROUND: Pharmaceutical industry-sponsored research has been shown to be biased toward reporting positive results. Frequent industry participation in trials assessing the efficacy of inhaled corticosteroid (ICS)

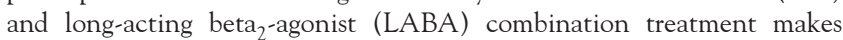
assessing industry influence difficult and warrants an assessment of specific potential publication bias in this area.

OBJECTIVE: To describe the frequency of industry involvement in ICS/ LABA trials and explore associations among significant outcomes, type of industry involvement and type of primary outcome.

METHODS: A systematic review of trials comparing ICS/LABA combination therapy with ICS monotherapy for asthma was conducted. Data concerning the type of industry sponsorship, primary outcome and statistical results were collected. Comparisons between type of sponsorship and significant results were analyzed using Pearson's $\chi^{2}$ test and relative risk. RESULTS: Of 91 included studies (median year of publication 2005 [interquartile range 1994 to 2008]), 86 (95\%) reported pharmaceutical involvement. Author affiliation was reported in 49 of 86 (57\%), and 19 of $86(22 \%)$ were industry-reported trials without full publications. The remainder were published journal articles. Studies with a first or senior author affiliated with industry were 1.5 times more likely to report statistically significant results for the primary outcome compared with studies with other types of industry involvement. Pulmonary measures were 1.5 times more likely to be statistically significant than were measures of asthma control. CONCLUSIONS: The potential biases identified were consistent with other research focused on author role and industry involvement, and suggest that degree of bias may vary with type of affiliation.

Key Words: Asthma; Bias; Evidence-based medicine; Inhaled corticosteroids; Systematic review

\section{La nature et l'influence de la participation de l'industrie pharmaceutique aux essais sur l'asthme}

HISTORIQUE : Il a été démontré que la recherche commanditée par l'industrie pharmaceutique a un parti pris pour des résultats positifs. En raison de la participation fréquente de l'industrie à des essais évaluant l'efficacité de la bithérapie de corticoïdes en aérosol (CEA) et de bêta agonistes de longue durée (BALD), il est difficile d'évaluer l'influence de l'industrie, ce qui justifie une évaluation des partis pris potentiels précis à ce sujet dans les publications.

OBJECTIF : Décrire la fréquence de la participation de l'industrie aux essais des CEA-BALD et explorer les associations entre les issues significatives, le type de participation de l'industrie et le type d'issues primaires.

MÉTHODOLOGIE : Les chercheurs ont effectué une analyse systématique des essais comparant la bithérapie de CEA-BALD à une monothérapie aux CEA contre l'asthme. Ils ont colligé les données portant sur le type de commandite de l'industrie, les issues cliniques et les résultats statistiques. Ils ont analysé les comparaisons entre le type de commandite et les résultats significatifs au moyen de la méthode du khi-carré de Pearson et du risque relatif.

RÉSULTATS : Sur les 91 études incluses (année médiane de publication : 2005 [plage interquartile de 1994 à 2008]), 86 (95\%) indiquaient une participation pharmaceutique. L'affiliation des auteurs était indiquée dans 49 de ces 86 études ( $57 \%$ ), et 19 des 86 études ( $22 \%$ ) étaient des essais déclarés par l'industrie sans publications complètes. Les autres étaient des articles publiés dans des revues. Les études dont l'auteur principal ou un auteur chevronné était associé à l'industrie étaient 1,5 fois plus susceptibles de faire état de résultats statistiquement significatifs à l'égard de l'issue primaire que les études profitant d'autres types de participation de l'industrie. Les mesures pulmonaires étaient également 1,5 fois plus susceptibles d'être statistiquement significatives que les mesures de contrôle de l'asthme.

CONCLUSIONS : Les partis pris potentiels confirmaient d'autres études portant sur le rôle de l'auteur et la participation de l'industrie et laissent croire que le degré de parti pris peut varier selon le type d'affiliation.

of industry (9). Some clinician-researchers (those who not only help produce but also will use the evidence from industry-sponsored trials) believe - quite reasonably - that the risk of bias varies with the strength of the conflict of interest (8). There may be substantial differences between the risks of bias resulting from industry associations such as industry authorship (industry employment of an author), contract research for industry, sponsorship of authors' speaking events/ tours, provision of equipment or supplies, and unrestricted educational or research grants. Nevertheless, the expanding empirical work on conflict of interest in biomedical research seems to be based primarily on the most serious conflicts such as large financial sponsorship of researchers, industry employees acting as authors or substantial industry management of trials $(5,10)$.

Although there is little question that industry has a financial interest in the outcome of asthma trials, blanket pronouncements of industry bias in asthma trials offer little insight into the actual measure of 


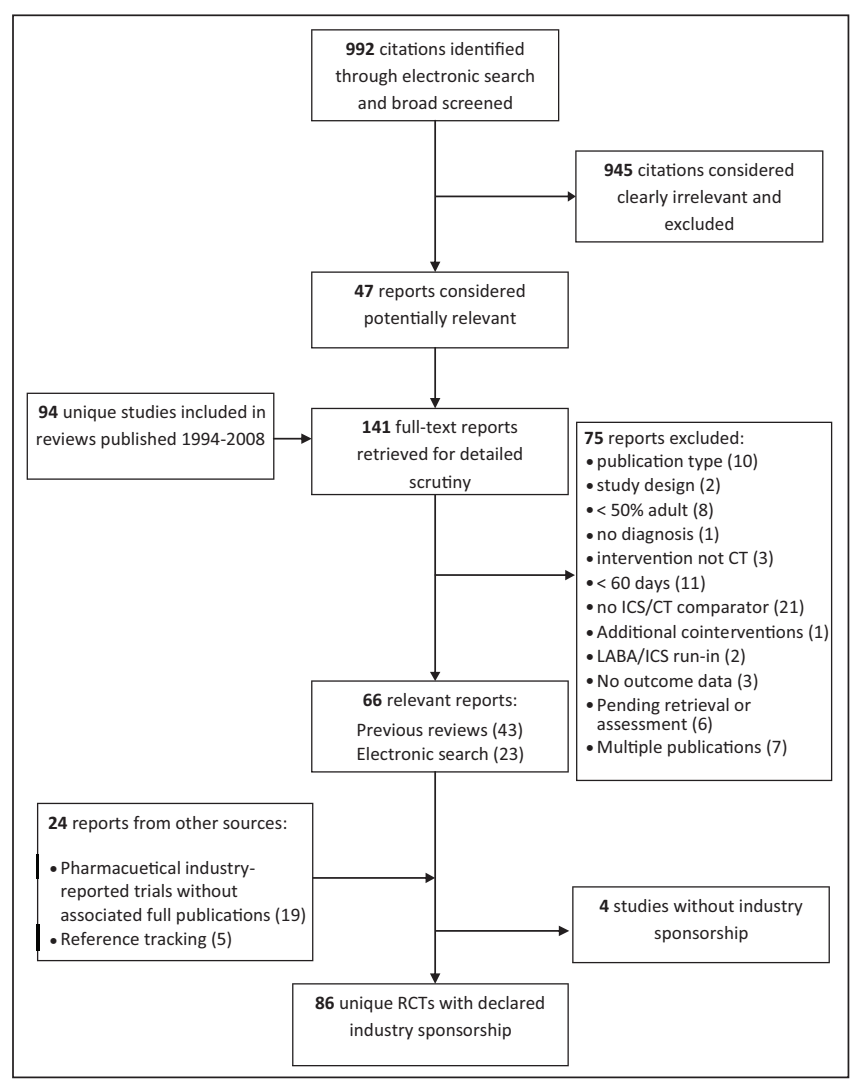

Figure 1) Results of the literature search and selection. CT Combination therapy; ICS Inhaled corticosteroid; LABA Long-acting beta 2 -agonist; RCTs Randomized controlled trials

influence of industry involvement on the reported results of comparative drug-effectiveness research and provide little help to health professionals who rely on the aforementioned categories of conflict of interest (or similar categories) when interpreting the results of such trials and systematic reviews of these trials. Moreover, in spite of the frequent involvement of industry in trials of asthma management, the landscape of the effect of potential conflicts of interest on published and unpublished asthma research results remains unexplored. The present study sought to describe, in greater detail, the nature of industry associations in trials comparing inhaled corticosteroid (ICS)/longacting beta 2 -agonist (LABA) combinations with ICS monotherapy and to consider possible associations among the type of industry involvement, investigator role and study outcome.

\section{METHODS}

\section{Study identification and selection}

The comprehensive search strategies for randomized controlled trials (RCTs) comparing ICS/LABA combination therapy and ICS monotherapy have been reported elsewhere (11). Briefly, searches of electronic databases including BIOSIS Previews, EMBASE, MEDLINE, CENTRAL and Web of Science were conducted. References to studies included in other reviews evaluating add-on LABAs were also screened and evaluated for inclusion. Pharmaceutical manufacturers were contacted for information regarding unpublished, completed or ongoing studies. Study selection was completed in two stages: a liberal screening stage based on the titles, subtitles, abstracts and keywords, and then a detailed review of the full-text of potentially relevant studies. Disagreements about inclusion or exclusion of studies were resolved either by consensus between two reviewers or by arbitration by a third reviewer. An included study had to be a primary report of an RCT (abstracts were excluded because data were frequently not sufficiently detailed to provide accurate assessment of study population parameters) that included $>50 \%$ adult patients ( $>12$ years of age) with a diagnosis of mild to severe persistent asthma but no comorbid pulmonary diseases (eg, bronchitis, cystic fibrosis, chronic obstructive pulmonary disease). The study must have taken place in a nonacute care setting and involved a comparison of ICS/LABA therapy (either fixed or variable dose) administered for a minimum of 60 days with ICS monotherapy of similar or higher dose than that used in combination therapy.

\section{Data extraction}

The following data were abstracted from each study: year of publication, source of funding and type of industry support, trial duration, number of participants randomized, assessment and reporting of participant compliance, primary outcome measure and definition, statistical results, and authors' conclusions as stated in both the abstract and main text. Data were extracted by one of three reviewers $(\mathrm{KB}, \mathrm{SB}$ and $\mathrm{JK})$ and verified independently by a second reviewer (KB, SB and JK).

\section{Data analysis}

Industry involvement was classified in one of seven ways: author affiliation; author affiliation and funding; funding only; support through data management or editing; unspecified support (ie, report says only 'supported by Company A'); industry involvement described but company not specified; or industry report.

'Author affiliation' with the supporting industry was defined as either the first or senior (last) author declaring in byline or conflict of interest statement at least one of the following: employed by the company; acted as a consultant or sat on advisory boards; was a paid lecturer or held grants (not further described); owned stock in the company; or held patent(s). For analysis, the pharmaceutical manufacturers were coded as companies A, B and C.

The primary outcome measures stated in these reports were classified into four categories: pulmonary function measures (eg, peak expiratory flow $[\mathrm{PEF}]$ or forced expiratory volume in $1 \mathrm{~s}\left[\mathrm{FEV}_{1}\right]$ ); asthma control measures (eg, exacerbations, symptom-free days, shortacting beta-agonist use); health-related quality of life measures; and nonclinical measures (eg, eosinophil counts, hyper-responsiveness). Outcomes for the investigation drug therapy (ICS/LABA) were classified as statistically significant at $\mathrm{P}<0.05$.

Frequencies were calculated and post hoc exploratory analysis was performed using Pearson's $\chi^{2}$ test (SPSS version 11.5.0 [IBM Corporation, USA] for Windows [Microsoft Corporation, USA]). Relative risks (RR) were calculated (Review Manager version 5.0, Copenhagen: The Nordic Cochrane Centre, The Cochrane Collaboration, 2008) for statistically significant associations. For all outcomes regarding treatment effects, statistical significance indicates a difference favouring ICS/LABA combination therapy over ICS monotherapy.

\section{RESULTS}

Of 91 included studies (median year of publication 2005 [interquartile range (IQR) 1994 to 2008]), 86 (95\%) studies were industry-involved reports comparing the effectiveness of ICS/LABA with ICS monotherapy (Figure 1). The most frequently reported type of industry involvement was 'author affiliation' (41\%). An additional 16\% reported both author affiliation and funding support; $22 \%$ were industry reports (considered de facto industry support). All studies were reported as being parallel-group RCTs. The majority (97\%) were multicentre trials ( $\geq 2$ centres). The median number of centres was 44 (IQR 18 to 70 ). The reports were published or reported elsewhere between 1994 and 2008 (median 2003.5 [IQR 2001 to 2006]). Most of the reports (67 of 86 [78\%]) were published as journal articles. The remaining industry-reported trial results (19 of 86 [22\%]) were available via publicly available internet databases (Table 1 ). The primary outcome in 54 trials (63\%) was a measure of pulmonary function, while patient-oriented outcomes (those reporting measures of asthma control) were selected as primary outcomes in 23 trials (27\%). 
TABLE 1 Study characteristics and results

\begin{tabular}{|c|c|c|c|}
\hline \multirow[b]{2}{*}{ Characteristic } & \multirow[b]{2}{*}{ Studies, n (\%) } & \multicolumn{2}{|c|}{$\begin{array}{l}\text { Significant result } \\
\text { (ie, } P<0.05), n\end{array}$} \\
\hline & & Yes & No \\
\hline \multicolumn{4}{|l|}{ Company involved } \\
\hline GlaxoSmithKline & $57(66)$ & 43 & 14 \\
\hline AstraZeneca & $22(26)$ & 19 & 3 \\
\hline Novartis & $4(5)$ & 4 & 0 \\
\hline Astra Draco & $1(1)$ & 1 & 0 \\
\hline Not specified & $2(2)$ & 2 & 0 \\
\hline \multicolumn{4}{|l|}{ Type of industry involvement } \\
\hline Author (first or last) affiliation & $35(41)$ & 32 & 3 \\
\hline Author affiliation and funding & $14(16)$ & 13 & 1 \\
\hline Industry report & $19(22)$ & 13 & 6 \\
\hline Involvement not described & $7(8)$ & 4 & 3 \\
\hline Funding & $5(6)$ & 3 & 2 \\
\hline Unspecified support & $4(5)$ & 3 & 1 \\
\hline Data management & $1(1)$ & 1 & 0 \\
\hline Editing & $1(1)$ & 0 & 1 \\
\hline \multicolumn{4}{|l|}{ Publication status } \\
\hline Journal article & $67(78)$ & 56 & 11 \\
\hline Industry report & $19(22)$ & 13 & 6 \\
\hline \multicolumn{4}{|l|}{ Primary outcome } \\
\hline Pulmonary & $54(63)$ & 51 & 3 \\
\hline Asthma control & $23(27)$ & 14 & 9 \\
\hline Nonclinical & $7(8)$ & 2 & 5 \\
\hline Quality of life & $1(1)$ & 1 & 0 \\
\hline Not specified & $1(1)$ & 1 & 0 \\
\hline Patient compliance reported & $30(35)$ & 27 & 3 \\
\hline \multicolumn{4}{|l|}{ Comparison } \\
\hline Same company drug & $65(76)$ & 50 & 15 \\
\hline Different company drug & $21(24)$ & 19 & 2 \\
\hline Significant result $(P<0.05)$ & $69(80)$ & NA & NA \\
\hline
\end{tabular}

NA Not applicable

Studies with author affiliation were almost 1.5 times as likely to report statistically significant effects for ICS/LABA combination agents compared with studies reporting other categories of involvement. Improved pulmonary function measures were 1.5 times as likely to be statistically significant compared with measures of asthma control (Table 2). There were no statistically significant associations between the particular industry involved and significant outcomes; however, company A was almost 3.5 times as likely to be involved in trials through author affiliation than through any other type of involvement. No other companies showed statistically significant differences among types of involvement.

\section{DISCUSSION}

There is a large amount of supportive evidence indicating the influence of conflict of interest resulting from industry association in pharmaceutical trials for many treatments $(1,3-7,10)$. As a result, industry involvement in studies included in comparative effectiveness reviews is a common concern for researchers, clinicians and policy makers who choose to use this evidence to help inform their decisions. The present post hoc exploratory analyses of the ICS/LABA asthma literature identified differences in associations between type of pharmaceutical industry involvement and statistically significant (ie, favourable) outcomes. Studies with at least one author affiliated with the supporting industry were more likely to report statistically significant effects favouring their combined investigational product, particularly if they selected pulmonary function measures as their primary outcome. Although no associations were found between the specific industry
TABLE 2

Associations among characteristics

\begin{tabular}{|c|c|c|}
\hline Association & Statistical test & $\mathbf{P}$ \\
\hline \multicolumn{3}{|l|}{ Report type $\times$ significant result } \\
\hline $\begin{array}{l}\text { Journal publication versus } \\
\text { industry report }\end{array}$ & $\chi^{2} 2.145, \mathrm{df}=1$ & $0.191^{*}$ \\
\hline \multicolumn{3}{|l|}{ Type of involvement $\times$ significant result } \\
\hline Overall & $\chi^{2} 13.862, \mathrm{df}=7$ & 0.054 \\
\hline $\begin{array}{l}\text { Author affiliation versus other } \\
\text { involvement }^{\dagger}\end{array}$ & $\chi^{2} 9.67, \mathrm{df}=1$ & $0.003^{*}$ \\
\hline $\begin{array}{l}\text { Author affiliation versus other } \\
\text { involvement }{ }^{\dagger}\end{array}$ & RR 1.42 (95\% Cl 1.10 to 1.82$)$ & NA \\
\hline \multicolumn{3}{|l|}{ Industry involved $\times$ significant result } \\
\hline Overall & $\chi^{2} 3.07, d f=4$ & 0.546 \\
\hline Company A versus other & $\chi^{2} 0.701, \mathrm{df}=1$ & $0.541^{*}$ \\
\hline Company $B$ versus other & $\chi^{2} 2.449, \mathrm{df}=1$ & $0.156^{*}$ \\
\hline \multicolumn{3}{|l|}{ Type of outcome $\times$ significant result } \\
\hline Overall & $\chi^{2} 24.586, \mathrm{df}=4$ & 0.000 \\
\hline Pulmonary versus other & RR 1.68 (95\% Cl 1.23 to 2.29$)$ & NA \\
\hline Asthma control versus other & RR 0.70 (95\% Cl 0.50 to 0.98$)$ & NA \\
\hline Pulmonary versus asthma control & RR 1.55 (95\% Cl 1.11 to 2.17$)$ & NA \\
\hline \multicolumn{3}{|l|}{ Type of involvement $\times$ industry involved } \\
\hline Author affiliation versus other & $\chi^{2} 12.27, \mathrm{df}=4$ & 0.015 \\
\hline Company A & RR 3.40 (95\% Cl 1.52 to 7.59$)$ & NA \\
\hline
\end{tabular}

${ }^{*}$ Fisher's exact test; ${ }^{+}$'Other involvement' was defined as being an industry report, receiving funding only, support through data management or editing, unspecified support or industry identified but involvement not described. NA Not applicable

sponsor involved and statistically significant outcomes, or between the type of report (journal article or industry report) and statistically significant outcomes, one company was more than three times as likely to be involved in trials through author affiliation than through any other type of involvement. This strong association between author affiliation (as defined here) implies that, if there is an association between author affiliation and results favouring the investigational treatment, the outcomes from trials conducted by this company are more likely to be positive than are those from trials conducted by other manufacturers. Finally, it should be highlighted that industry reports were less likely to be positive than journal articles, which suggests that industry is not publishing its negative trials (although it is making them publically available in trial registries and on its own websites). The reason for this may be industry, investigator fatigue or the general issue of publication bias whereby studies reporting negative results are less often published.

The finding that studies with at least one author affiliated with the supporting industry were more likely to report significant effects favouring their combined investigational product supports the belief that the risk and degree of bias varies with the strength of potential conflict of interest and author role (8). Although the reporting of conflicts of interest was not always detailed, it was reported clearly and consistently enough to undertake this initial examination. Nevertheless, given what we know about the structure of industry involvement in research, analysis and publication, it is likely that the self-reported conflicts used here do not provide a complete picture of the actual structures of industry involvement (12-14).

The results of the present study suggest the presence of two potential biases: a reporting outcome bias (ie, outcomes with unfavourable results are suppressed in favour of those outcomes with favorable results) (15); and an interpretive and rhetorical effects bias (ie, data are not omitted, but are presented and interpreted in ways that favour the authors' interests) (1). Examining the number and type of secondary outcomes and comparing authors' conclusions with the statistical results for all outcomes would shed light on which of these biases is more prevalent. 
Only one-quarter of the trials selected patient-oriented outcomes as the primary outcome. The reason for the selection of pulmonary function outcomes may be multifactorial; however, it is likely that some requirement by governing/licensing agencies may have played a role. Nevertheless, it should be noted that, even if these outcomes were required by a regulator, there is an inherent bias in selecting flow rates $\left(\mathrm{PEF}\right.$ and $\mathrm{FEV}_{1}$ ) as a primary end point when comparing LABA/ ICS combination therapy with ICS monotherapy. A comprehensive systematic review of this literature (11) highlighted the discrepancy between the apparent benefit of combination therapy over monotherapy based on lung function measures compared with the more modest benefit based on symptom control and quality of life measures. However, patient-oriented outcomes such as quality of life, while highly reliable, are more difficult to collect, especially in long-term follow-up studies. Composite outcomes, such as those in the Asthma Control Questionnaire, are more likely to be clinically relevant because they reflect the symptoms and changes in airway calibre. Ultimately, the occurrence of exacerbations is likely to be one of the most clinically relevant outcomes because it has the greatest impact on the patient and on the cost to society $(16,17)$.

The involvement of industry in all of the asthma trials examined here precluded an examination of the influence of industry versus nonindustry support on trial results. Additionally, a comparison of results between large ( $>100$ participants) and small trials, potentially revealing because of a known association between large trials and positive results (18), could not be performed because the majority of trials $(87 \%)$ were large. For this reason, an assessment of industry involvement on magnitude of treatment effect may have been more revealing.

Finally, when significant results regarding treatment efficacy are not found, studies may sometimes inappropriately draw conclusions about treatment equivalence or noninferiority. Assessing this aspect of the trials would also have added a level of complexity and detail to the analysis that may have been more revealing. Nevertheless, assessments of the association between the significance of results and industry sponsorship is important because authors and readers of medical research papers frequently draw conclusions about the comparative effectiveness of interventions based on the report of statistical significance (19).

There are several weaknesses in the present study. First and foremost is the fact that the small number of nonindustry asthma trials (five of 91) precluded a subgroup comparison between the influence of industry versus nonindustry support on trial results. Lacking this comparison subgroup, the study results are only suggestive of an association between authorship and positive results. For example, it may be that the apparent bias associated with author affiliation may just mean that manufacturers are successful at enlisting opinion leaders to contribute to their high-profile studies. Future studies comparing industry-sponsored and nonindustry-sponsored trials may help to shed additional light on the potential biases associated with different forms of industry sponsorship.

Second, the 'author affiliation' category combined five types of affiliation (eg, authors who were employed by the manufacturer, those acting as consultants or advisory board members, paid lecturers or grant holders, owners of stock in the company and patent holders). It is plausible that the various forms of association within this group differ with respect to the potential degree of conflict of interest and the influence this conflict exerts on study outcomes. As such, a more granular analysis of these associations may offer greater insight into the mechanisms and degree of influence of these associations on the direction and magnitude of trial results.

Third, the categorization of author affiliation was made only for the primary or senior author based on the conflict of interest statements provided by the authors. This decision was based on the assumption that the primary and senior authors of studies are most likely to influence the presentation of results. We believe this was a reasonable assumption given the increasing trend to designate senior researchers as first and senior authors over more junior researchers (20). If industry authors typically appear as middle authors and this authorship is an indicator of industry management of the research and publication and, hence, of an associated bias, this would underestimate the differences between the groups. The large number of authors in the studies precluded any meaningful evaluation of their individual influence. It is also likely that influences other than type of author affiliation and reporting biases exist, which we could not uncover in the present analysis (21).

Finally, we relied on reported statements of industry affiliation or involvement to determine author involvement and did not validate these potential conflicts by contacting the authors, examining their curriculum vitaes, their past publications or other strategies. Previous research has also suggested that industry-sponsored research reporting results favourable to the company product are more likely to be published as abstracts (4). Because we excluded abstracts, our results are likely to be a conservative estimate of the influence of industry sponsorship on trial results.

Barring the complete sequestration of research and industry $(22,23)$, the potential bias introduced by industry associations will continue to be a problem for reviewers, clinicians and policy makers, especially in areas of research in which industry is frequently involved. In such cases, researchers who depend on the involvement of industry can do no better than to follow existing guidelines for the ethical conduct of industry-physician relationships (24), and readers of the results of such research will have to rely on authors to openly declare competing interests and to trust that researchers have minimized the potential influence of these relationships. For these reasons, the results of the present study complement - but also challenge - the conclusions of research regarding claims of a pharmaceutical industry bias that has not examined the type and degree of industry involvement. Furthermore, the present examination, and similar others (9), both support and are supported by the development and use of more comprehensive and rigorous standards for reporting authorship roles and potential conflicts of interest (25).

The findings of the exploratory analyses highlight the importance of and need for mandatory and accurate statements of conflicts of interest and author contributions - a need that has been highlighted by the recent publication of a rigorous checklist for financial conflict of interest and author contribution (25). Future studies comparing industry-sponsored and nonindustry-sponsored trials may help to shed light on the potential biases associated with different forms of industry sponsorship. The fact that so many trials were unpublished and reported nonclinically important measures as primary outcomes remains a concern. In light of the observations made here, there is a need for regulatory bodies, clinicians interested in asthma management and patient advocacy groups to request trials with clinically relevant and patient-oriented outcomes as primary study outcomes.

\section{CONCLUSIONS}

The associations described in the present article support further investigation into the nature and influence of industry involvement in drug efficacy trials, especially in topic areas such as asthma treatment where industry sponsorship is frequent but also variable and, hence, where the influence of potential conflicts of interest may also vary. Greater insight into these variations would be facilitated by mandatory and detailed statements of conflicts of interest and author contributions, and the reasons for the selection of study outcomes.

ACKNOWLEDGEMENTS: The authors thank research assistants at the University of Alberta Evidence-based Practice Center (Simon Bow, Jeffrey Klassen, and Kathleen Wagontall) for their help with study selection and data extraction.

AUTHOR CONTRIBUTIONS: KB coordinated the project, conducted statistical analysis and assisted with all other phases of the project; CL provided content expertise in clinical asthma management and contributed 
to writing; LT designed and executed the literature search strategies, wrote the associated search strategy section of the report and managed the bibliographic software; BHR acted as the overall research lead, provided content expertise in clinical asthma management, and assisted with statistical analysis and all other phases of the project. All authors approved the final version of the manuscript.

FUNDING/SUPPORT: The literature search and selection was conducted for a health technology assessment report contracted by the Canadian Agency for Drugs and Technologies in Health. No other external funds were used to support this research. Dr Rowe's research is supported by a Tier 1 Canada Research Chair in Evidence-based Emergency Medicine from the Canadian Institutes of Health Research (CIHR) through the Government of Canada (Ottawa, ON).

CONFLICTS OF INTEREST DISCLOSURE: KB, CS, and LT have no conflicts of interest to disclose. CL has received funds from GlaxoSmithKline for an investigator-initiated study, consulting fees from GlaxoSmithKline, AstraZeneca, and Novartis, and speaker fees from AstraZeneca, GlaxoSmithKline, and MerckFrosst. In the past two years, BHR has received funding from GlaxoSmithKline (Canada) for an investigator-initiated study and MedImmune (USA) for industry-initiated studies.

\section{REFERENCES}

1. Liss H. Publication bias in the pulmonary/allergy literature: Effect of pharmaceutical company sponsorship. Isr Med Assoc J 2006;8:451-4.

2. Chan AW, Krleza-Jeric K, Schmid I, Altman DG. Outcome reporting bias in randomized trials funded by the Canadian Institutes of Health Research. CMAJ 2004;171:735-40.

3. Jorgensen AW, Maric KL, Tendal B, Faurschou A, Gøtzsche PC. Industry-supported meta-analysies compared with meta-analyses with non-profit or no support: Differences in methodological quality and conclusions. BMC Med Res Methodol 2008;8:60.

4. Lexchin J, Bero LA, Djulbegovic B, Clark O. Pharmaceutical industry sponsorship and research outcome and quality: Systematic review. BMJ 2003;326:1167-70.

5. Sismondo S. Pharmaceutical company funding and its consequences: A qualitative systematic review. Contemp Clin Trials 2008;29:109-13.

6. Turner E, Matthews AM, Linardatos E, Tell RA, Rosenthal R. Selective publication of antidepressant trials and its influence on apparent efficacy. N Engl J Med 2008;358:252-60.

7. Als-Nielsen, Chen W, Gluud C, Kjaergard LL. Association of funding and conclusions in randomized drug trials. JAMA 2003;290:921-8.

8. McGregor M, Xie X, Dendukuri N. The use of quality instruments to weight evidence from RCTs [oral presentation]. $2011 \mathrm{CADTH}$
(Canadian Agency for Drugs and Technologies in Health) Symposium, Vancouver, British Columbia, April 4, 2011.

9. Jagsi R, Sheets N, Jankovic A, Motomura AR, Amarnath S, Ubel PA. Frequency, nature, effects, and correlates of conflicts of interest in published clinical cancer research. Cancer 2009;115:2783-91.

10. IOM (Institute of Medicine). Conflict of Interest in Medical Research, Education, and Practice. Washington, DC: The National Academies Press, 2009

11. Bond K, Coyle D, O'Gorman K, et al. Long-acting beta -agonist $^{-}$ and inhaled corticosteroid combination therapy for adult persistent asthma: Systematic review of clinical outcomes and economic evaluation [Technology report number 122]. Ottawa: Canadian Agency for Drugs and Technologies in Health, 2009.

12. Fugh-Berman A, Dodgson S. The ethics of publication planning in the pharmaceutical industry. Open Med 2008;2:e33-6.

13. Matheson A. Corporate science and the husbandry of scientific and medical knowledge by the pharmaceutical industry. Biosocieties 2009;3:355-82.

14. Sismondo S. Ghost management: How much of the medical literature is shaped behind the scenes by the pharmaceutical industry? PLoS Medicine 2007;4:e286.

15. Sterne J, Egger M, Moher D, editors. Chapter 10: Addressing reporting biases. In: Higgins JPT, Green S, eds. Cochrane handbook for systematic reviews of interventions. Version 5.0.1 [updated September 2008] ed. Oxford: The Cochrane Collaboration; 2008;1:297-333.

16. Krahn MD, Berka C, Langlois P, Detsky AS. Direct and indirect costs of asthma in Canada, 1990. CMAJ 1996;154:821-31.

17. Van Ganse E, Laforest L, Pietri G, et al. Persistent asthma: disease control, resource utilization and direct costs. Eur Resp J 2002;20:260-7.

18. Singh J, Murphy S, Bhandari M. Trial sample size, but not trial quality, is associated with positive study outcome. J Clin Epidemiol 2009;63:154-62.

19. Goodman SN. Toward evidence-based medical statistics. 1: The p value fallacy. Ann Intern Med 1999;130:995-1004.

20. Drenth JPH. Multiple authorship. The contribution of senior authors. JAMA 1998;280:219-21.

21. Sackett DL, Oxman AD. HARLOT plc: An amalgamation of the world's two oldest professions. BMJ 2003;327:1442-5.

22. Doucet M, Sismondo S. Evaluating solutions to sponsorship bias. J Med Ethics 2008;34:627-30.

23. Schafer A. Biomedical conflicts of interest: A defence of the sequestration thesis - learning from the cases of Nancy Olivieri and David Healy. J Med Ethics 2004;30:8-24.

24. Coyle SL. Ethics and Human Rights Committee, and American College of Physicians-American Society of Internal Medicine. Physician-industry relations. Part 1 . Individual physicians. Ann Intern Med 2002;136:396-402.

25. Rochon P, Hoey J, Chan AW, et al. Financial conflicts of interest checklist 2010 for clinical research studies. Open Med 2010;4:e69. 


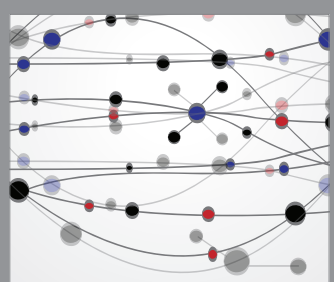

The Scientific World Journal
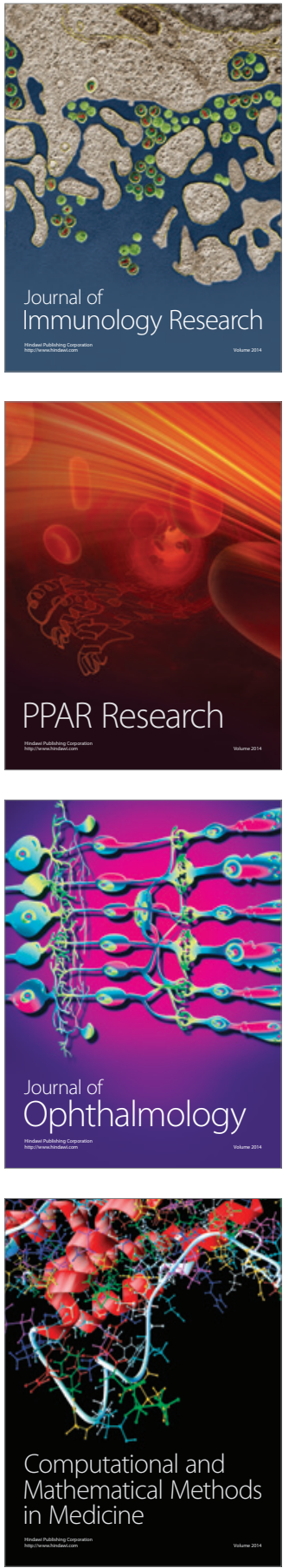

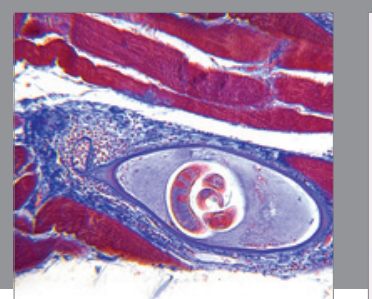

Gastroenterology Research and Practice

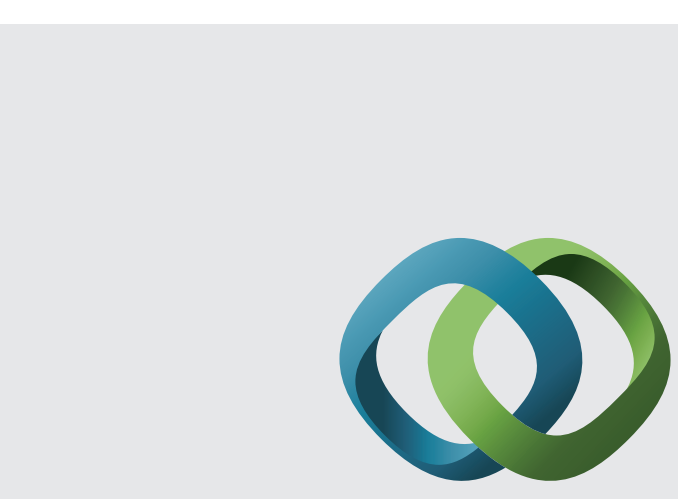

\section{Hindawi}

Submit your manuscripts at

http://www.hindawi.com
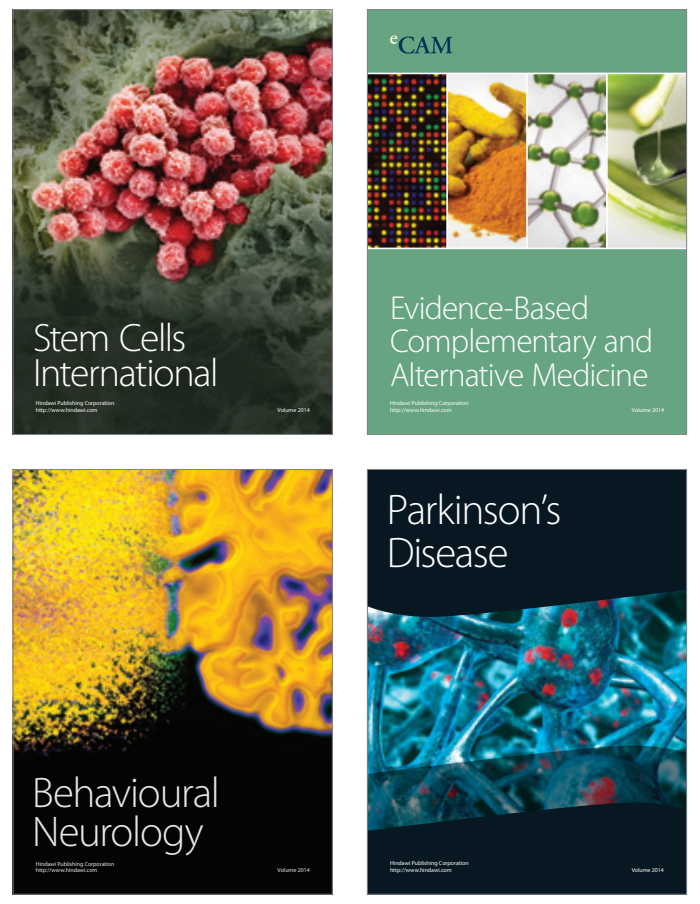
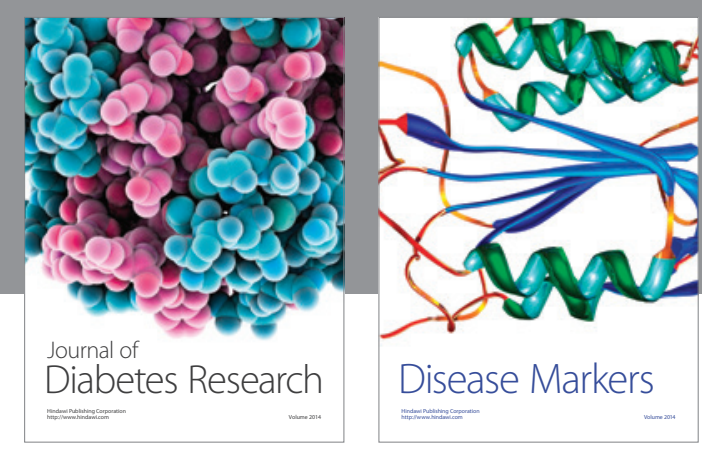

Disease Markers
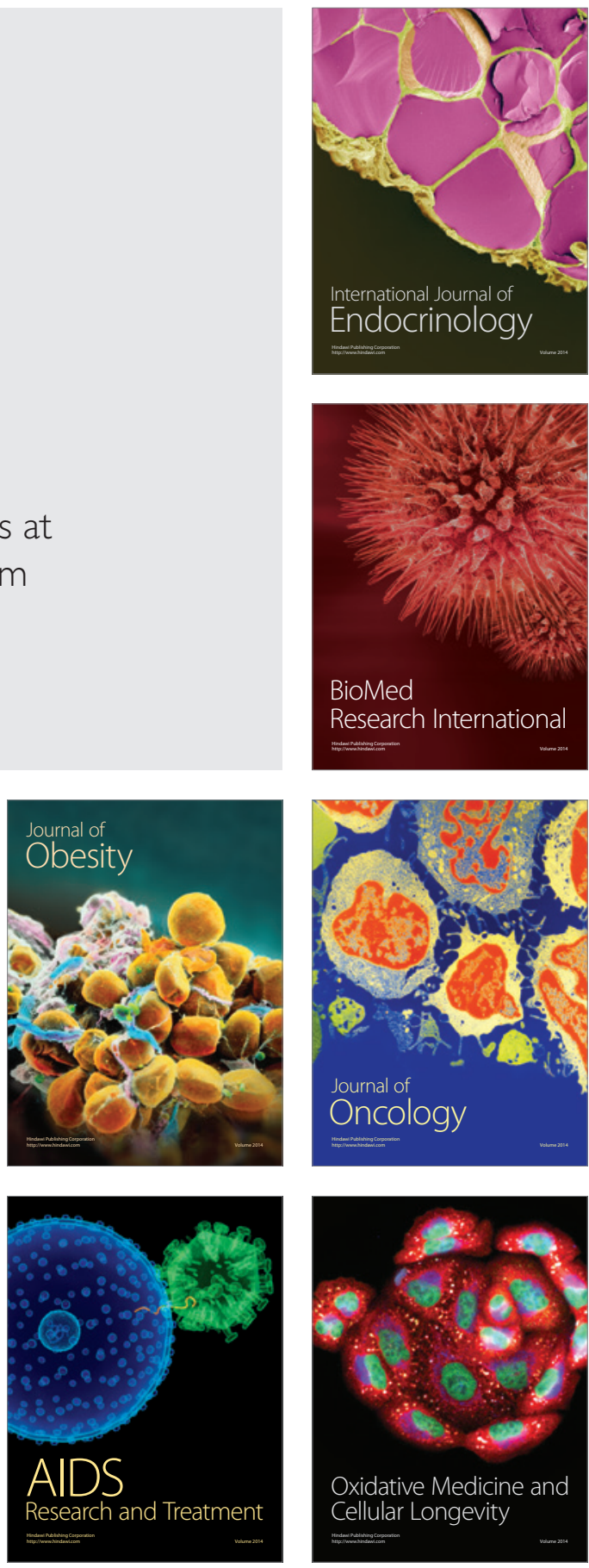